\title{
TREATMENT OF FEMORAL FRACTURE IN THE CHILD WITH HEAD INJURY
}

\author{
ISRAEL ZIV, MERCER RANG
}

From the Hospital for Sick Children, Toronto

\begin{abstract}
The outcome of various types of treatment for femoral fracture in children with head injury was studied retrospectively in 51 patients with 56 fractures. Of these, 36 patients (71 per cent) were in deep coma and scored 5 to 7 on the Glasgow scale. Forty-three children (84 per cent) were eventually able to walk freely. Open reduction and internal fixation proved an attractive solution for femoral fractures in children with head injury who could tolerate general anaesthesia: intramedullary nailing was safe and gave satisfactory results in 16 fractures but infection complicated three of the five fractures which were plated.
\end{abstract}

Femoral fractures are difficult to treat in the child with a head injury. Traction may be contra-indicated because the head-down position must be avoided, while skeletal traction may fail due to spasticity and restlessness. Poor results after closed reduction have led some authors to advocate open reduction and internal fixation (Fry, Hoffer and Brink 1976), which facilitates overall care. However, open reduction is only possible if the child is fit for general anaesthesia. We report our experience in treating children with head injuries and femoral fractures at the Hospital for Sick Children, Toronto.

\section{CLINICAL MATERIAL}

Between 1971 and 1980, 122 children with a fractured femur and severe head injury, as defined on the Glasgow coma scale (Teasdale and Jennett 1974), were admitted through the Emergency Department. We excluded from our retrospective study the 14 patients who died before definitive treatment of the fracture was started and the 57 who recovered from the head injury within three days. This left 51 children, including five with bilateral fractures.

There were 29 boys and 22 girls ranging in age from seven months to 15 years (average 8.4 years). Motor vehicle accidents accounted for most of these injuries; only four children had fallen from a height. The duration of follow-up was between 2 and 10 years (mean 6.4 years).

The largest group of patients was comatose for 7 to 30 days (Table I). Almost half of the children were pre-

I. Ziv, MD, FRCS(C)

Department of Orthopaedics, I Ramabain Medical Centre, Haifa, Israel.

M. Rang, FRCS, FRCS(C), Senior Staff Surgeon

The Division of Orthopaedic Surgery, The Hospital for Sick Children, 555 University Avenue, Toronto, Ontario, Canada M5G IX8.

Requests for reprints should be sent to Dr M. Rang.

(C) 1983 British Editorial Society of Bone and Joint Surgery 0301-620X/83/3026-0276\$2.00 adolescents (aged 6 to 12 years) who scored 5 to 7 on the Glasgow scale. Left-sided fractures outnumbered those on the right by 34 to 22 (five were bilateral). Thoracic or intra-abdominal injuries and fractures of the other limbs were also present in 36 children ( 70.6 per cent) (Table II).

Table I. Severity and duration of coma

\begin{tabular}{|lccl|}
\hline $\begin{array}{l}\text { Duration of coma } \\
\text { (days) }\end{array}$ & \multicolumn{3}{l|}{ Coma scale* } \\
\cline { 2 - 4 } & $5-7$ & $8-11$ & $12-15$ \\
\hline $3-6$ & 12 & 6 & 1 \\
$7-30$ & 16 & 7 & - \\
$>30$ & 8 & 1 & - \\
TOTAL & 36 & 14 & 1 \\
\hline
\end{tabular}

* Coma scale : severe (5-7); moderate (8-11); mild $(12-15)$

Table II. Associated injuries (in 36 patients)

\begin{tabular}{|llll|}
\hline Visceral injuries (17) & & Skeletal injuries (24) & \\
Haemothorax & 4 & Skull & 9 \\
Respiratory distress syndrome & 4 & Clavicle & 5 \\
Diaphragmatic tear & 1 & Second rib & 2 \\
Intra-abdominal & 4 & Forearm & 3 \\
Ruptured spleen & 3 & Humerus & 2 \\
Duodenal & 1 & Pelvis & 1 \\
& & Tibia & 2 \\
\hline
\end{tabular}

\section{METHODS}

Most patients were treated initially with skin traction in a Thomas' splint. This technique was continued if reduction was maintained and coma was short-lived or death seemed imminent. Failure of skin traction was the indication for either skeletal traction or internal fixation. 
Skin traction was used definitively to treat most children under five years, while intramedullary nailing was the most common treatment in patients between 6 and 12. Skeletal traction was also used, particularly in pre-adolescents, a femoral or tibial pin being inserted in the distal metaphysis. Plate fixation was used in four preadolescents, including one patient who had bilateral plating. In one of our patients a Wagner apparatus was used as an external fixator after unsuccessful traction.

\section{RESULTS}

Fracture healing. Of the 56 fractures, 47 (84 per cent) healed with satisfactory clinical results at final follow-up; that is with measured clinical shortening of less than 1.0 centimetres or angular deformity of less than 10 degrees (Table III). No child encountered long-term knee stiffness reduced anatomically. The leg was 1.5 centimetres longer, which had no clinical significance after five years' followup.

Malunion. In three children under 12 skeletal traction failed to prevent angular deformities and shortening. One had anterior bending of 30 degrees. The other two had varus deformities that necessitated osteoclasis. Another child, because of severe spasticity, experienced dislocation of the contralateral hip which was diagnosed after 18 months of tetraplegia and then treated by shortening osteotomy.

Complications of surgery. Open reduction with plate fixation resulted in infection in three of the five fractures on which it was performed. One of these children had bilateral fractures, arterial injury and septicaemia.

Fat embolism was suspected in six children who

Table III. Results of various methods of treating fractured femur in different age groups

\begin{tabular}{|c|c|c|c|c|c|c|c|}
\hline \multirow[b]{3}{*}{ Age } & \multicolumn{3}{|c|}{ CLOSED REDUCTION } & \multicolumn{3}{|c|}{ OPEN REDUCTION } & \multirow[t]{3}{*}{ TOTAL } \\
\hline & \multirow[b]{2}{*}{ Skin traction } & \multicolumn{2}{|c|}{ Skeletal traction } & \multicolumn{2}{|c|}{ Intramedullary nail } & \multirow[b]{2}{*}{ Plate } & \\
\hline & & Femoral pin & Tibial pin & Kuntscher & Rush & & \\
\hline \multicolumn{8}{|l|}{$0-5$ years } \\
\hline Satisfactory & 9 & 2 & 2 & $\mathbf{0}$ & 1 & 0 & 14 \\
\hline Unsatisfactory & 0 & 1 & 0 & 0 & 0 & $\mathbf{0}$ & 1 \\
\hline \multicolumn{8}{|l|}{$6-12$ years $^{*}$} \\
\hline Satisfactory & 5 & 7 & 2 & 8 & 4 & 2 & 28 \\
\hline Unsatisfactory & $\mathbf{0}$ & 2 & 0 & $\mathbf{0}$ & 0 & 3 & 5 \\
\hline \multicolumn{8}{|l|}{$13-15$ years } \\
\hline Satisfactory & 0 & 1 & 0 & 3 & $\mathbf{0}$ & $\mathbf{0}$ & 4 \\
\hline Unsatisfactory & 3 & 0 & 0 & 0 & $\mathbf{0}$ & 0 & 3 \\
\hline \multicolumn{8}{|l|}{ TOTAL } \\
\hline Satisfactory & 14 & 10 & 4 & 11 & 5 & 2 & 46 \\
\hline Unsatisfactory & 3 & 3 & 0 & 0 & $\mathbf{0}$ & 3 & 9 \\
\hline
\end{tabular}

* The child with an external fixator has been excluded

after traction or infection after intramedullary nailing. Walking ability was not influenced by the femoral fracture; however, malunions and leg-length discrepancy caused a limp in six children.

Leg length. In three patients over 12 years old skin traction resulted in clinically apparent shortening of the fractured leg. Altogether, shortening exceeded one centimetre in seven fractures ( 12.5 per cent). Six overrode while undergoing skin or skeletal traction, and one child underwent prophylactic shortening at the time of plating, which resulted in malrotation and a short femur. Three children in whom shortening was more than 2.5 centimetres required epiphysiodesis to equalise leg length.

Overgrowth affected only one femur that had been were treated by closed reduction and who were comatose for longer than one week. Deterioration of consciousness occurred at the same time in these patients but they all recovered uneventfully.

Neurological outcome. Right-sided hemiplegia occurred in seven children who had left-sided fractures. There was no correlation between the side of the fracture and the severity or duration of coma.

Nine children have suffered from seizures since their injury but only two have required treatment for epilepsy. Spasticity was the outcome in seven children, of whom two now walk with an ataxic gait and one is able to walk indoors only. Most children who were comatose for less than $\mathbf{3 0}$ days were able to walk freely out of doors at final 
follow-up (39 children). Of the nine who were unconscious for more than one month, four became able to walk freely (two with an ataxic gait) and five remained in a vegetative state.

\section{DISCUSSION}

Despite severe, prolonged coma in some cases, 43 children ( 84 per cent) were able to walk freely out of doors by the end of the follow-up, indicating a much better functional outcome than in adults (Miller et al. 1981). Prognosis in children is markedly improved when intracranial pressure is monitored and urgent attention given when it is raised. Since children with a Glasgow coma score over 5 tend to recover fully (Bruce et al. 1978), the femoral fracture should be treated on the assumption that locomotor recovery will be complete.

The main problems in treating these difficult injuries are spasticity and restlessness, as well as the need to avoid the head-down position (Rang 1974). Spasticity is common with brain-stem injuries. Restlessness may be due to contusion or laceration of the frontal lobe, hypoxia or to an overdistended bladder. Femoral pin traction in a restless child has disadvantages: it is a portal of entry for infection so that delayed intramedullary nailing is not advisable; and the patient is wriggling around in bed for three weeks and is then in a spica cast, thus making both immobilisation and mobilisation difficult.

Open reduction of femoral fractures is very appeal- ing. It provides immediate fixation, which eases nursing care and spares the surgeon daily worry about the position of the fracture. The incidence of malunion in our series was six of 34 fractures which underwent traction compared with none of the 16 which had intramedullary fixation. However, there is some risk of avascular necrosis of the femoral head (Herzog, Affolter and Jani 1976) and of infection, although our patients did not experience these complications.

Plating was used in five cases because of the hazard of avascular necrosis and to give more certain control of rotation. This was a mistake: three of the five fractures became infected. We believe the infections were related to the large number of tubes attached to these patients and their decreased resistance. Another disadvantage is that the plate must be removed, a relatively extensive surgical procedure.

Overgrowth was not a problem after open reduction and it is a mistake to shorten the bone at that time. There was no difference in clinically apparent leg shortening between our results with open reduction and those of Reynolds (1981) with closed reductions.

We advocate prophylactic antibiotics in those with multiple injuries because of the numerous portals of entry for infection. For children up to five years old who have head injuries and fractured femora we recommend skin traction. In those older than five, intramedullary fixation appears the most satisfactory treatment.

\section{REFERENCES}

Bruce DA, Schut L, Bruno LA, Wood JH, Sutton LN. Outcome following severe head injuries in children. J Neurosurg 1978;48:679-88. Fry K, Hoffer MM, Brink J. Femoral shaft fractures in brain-injured children. J Trauma 1976;16:371-3.

Herzog B, Affolter P, Jani L. Late results following marrow nailing of femur fractures in childhood. Z Kinderchir 1976; 19:74-80.

Miller JD, Butterworth JF, Gudeman SK, et al. Further experience in the management of severe head injury. J Neurosurg 1981;54:289-99.

Rang M. Children's fractures. Philadelphia: JB Lippincott, 1974.

Reynolds DA. Growth changes in fractured long-bones: a study of 126 children. J Bone Joint Surg [Br] 1981;63-B:83-8.

Teasdale G, Jennett B. Assessment of coma and impaired consciousness: a practical scale. Lancet 1974;ii:81-4. 